\title{
O papel da tradição na construção do mundo histórico ${ }^{1 *}$
}

The role of tradition in the construction of the historical world

Augusto Bruno de Carvalho Dias Leite ${ }^{2}$ 
Resumo: Através da exposição inicial do significado da tradição para Martin Heidegger, Sigmund Freud e Walter Benjamin, proponho-me a analisar as implicações ontológicas e epistemológicas que a tradição identificada com a transmissão cultural produz para a compreensão histórica. Para tanto, a impessoalidade (Heidegger), a estrutura super-egoica (Freud) e a transmissibilidade (Benjamin) serão examinadas por este artigo à luz do conceito de passado como o limite-criativo do tempo em conexão com a tradição - apresentada como condição existencial. Palavras-chave: Tradição; Passado; Existência; História.

\begin{abstract}
Throughoneinitialexpositionon themeaningof tradition in Martin Heidegger, Sigmund Freud and Walter Benjamin, I would like to analyze the ontological and epistemological implications that tradition (identified with cultural transmission) produces for historical understanding. For this, the impersonality (Heidegger), the superegoic structure (Freud) and the transmissibility (Benjamin) will be examined by this article in the light of the concept of past as the creative-limit of time in conexion with tradition - presented as an existential condition.
\end{abstract}

Keywords: Tradition; Past; Existence; History. 
Ninguém nos amassa novamente na terra e barro, ninguém conjura nosso pó. Ninguém.

(Psalm, Paul Celan)

\section{Apresentação do problema}

As obras de Martin Heidegger e Sigmund Freud auxiliam efetivamente na compreensão do fenômeno da transmissão cultural enquanto expressão da tradição, bem como o trabalho de Walter Benjamin expõe as implicações epistemológicas desta estrutura da existência para o entendimento do fenômeno histórico.

Inicialmente, a tradição, para Benjamin, Heidegger e Freud, configura-se como um processo de continuidades e também de rupturas. Não se trata apenas da sucessão natural entre o antes e o depois, mas de um movimento por meio do qual há tanto escolhas quanto imposições. Neste cenário, há a disputa entre forças fundamentalmente existenciais (a tradição é a "estrutura" espiritual da sociedade), entre aquilo que de alguma maneira possibilita a história: os passados.

Nestes termos, proponho explorar neste artigo a ideia de tradição não como mero conteúdo estático e decantado de determinada cultura. Na verdade, a partir das reflexões de Heidegger, Freud e Benjamin, gostaria de apresentar a tradição como a substância da cultura e o próprio ato de transmissão cultural, atividade existencial e social orgânica. Walter Benjamin certamente é quem transporta o problema da tradição para os limites da história, mais precisamente do fenômeno histórico, não da prática da historiografia. Contudo, é possível extrair de Heidegger meditações importantes sobre o papel da tradição na alienação existencial, que o filósofo irá chamar de impessoalidade; bem como localiza-se na obra de Freud a definição de uma estrutura super-egoica a qual o $E u$ estaria submentido, condicionado, limitado. Trata-se, enfim, da demonstração do fenômeno da tradição/transmissão como uma das condições existenciais elementares para se compreender a construção do mundo histórico, que possui uma conexão umbilical com o caráter inacabado e aberto do conceito de passado, o átomo fundamental da ideia de tempo, que participa tanto dos fenômenos da tradição como do histórico; três diferentes elementos (tempo, tradição e história) que podem ser pensados conjuntamente. ${ }^{3}$

Finalmente, ressalto que a perspectiva analítica aqui apresentada se dedica a exposição de um problema teórico, cujas relações com seu momento histórico 
e intelectual se resumem no chamado "problema do historicismo" (SCHOLTZ, 1989; TROELTSCH, 1913), identificado no princípio do século XX europeu. Apesar desse fato, o argumento deste artigo privilegia, então, o desenvolvimento de uma questão teoricamente, sem evidenciar sua origem ou contexto; um limite declarado deste texto (como muitos outros) que, contudo, não acarreta prejuízo ao exame restrito aqui proposto.

\section{O modo de ser impessoal é a tradição soberana}

\section{A impessoalidade}

Na língua alemã, o pronome indefinido man [se, no português; on, no francês; one, no inglês] é o artifício linguístico para a indeterminação. Martin Heidegger, no conhecido tratado de 1927, Sein und Zeit [Ser e Tempo], utiliza “das Man” para dizer da "impessoalidade" da existência [Dasein]; quer dizer, quando o seu modo de ser se distancia de si mesmo e recai na impessoalidade, a existência torna-se o impessoal [das Man; a-gente ${ }^{4}$. Quando do distanciamento inerente ao ser, em que ele está com os outros como ser-com [Mitsein], mas se esquecendo do "si mesmo", o Dasein fica sujeito aos outros, e apenas aos outros.

\footnotetext{
'Os outros', como a-gente os chama, para encobrir nossa própria essencial pertinência a eles, são aqueles que no cotidiano serum-com-o-outro de pronto e no mais das vezes 'são aí'. O que não é este nem aquele, nem a-gente mesma, nem alguns, nem a soma de todos. O ‘quem’ é o neutro: a-gente [o impessoal]. (GA, I, 2, 168-169) (HEIDEGGER, 2012, p. 363-365).
}

No uso dos meios públicos em geral, jornais, publicidade, etc., o impessoal ou a impessoalidade exerce uma verdadeira ditadura do das Man. O § 27 do tratado sobre as relações entre ser e tempo é dedicado a este modo de ser da existência que, não sendo ela mesma ou se distanciando de si, à procura de ser com ou ser junto com os outros, acaba por se radicalizar e não ser ninguém, fazendo desaparecer as diferenciações e expressividades próprias à existência. De sercom os outros, a existência passa, então, a ser-um-entre-outros. Pois “A-gente [Das Man; o impessoal], com a qual se responde à pergunta pelo quem do Dasein cotidiano, é o Ninguém ao qual todo Dasein já se entregou cada vez em seu ser-um-entre-outros” (GA, I, 2, 170) (HEIDEGGER, 2012, p. 367). O impessoal, portanto, é ninguém [Niemand]. 


\title{
0 encontro com a historicidade como fuga da impessoalidade
}

A resposta encontrada pela existência, que se diz não ser ninguém, perdida entre outros, impede de maneira decisiva o conhecimento de si do ser, ou do encontro com sua historicidade; deixando, assim, a existência sujeita ao que Heidegger nomeia impropriedade, cuja necessária relação se estabelece com o movimento natural da tradição, e não da história.

\begin{abstract}
A-gente [impessoal] evita a escolha. Cega para possibilidades, é incapaz de repetir o ter sido, mas só retém e conserva o 'real' que restou do histórico-mundial já sido, os restos e as informações subsistentes a tal respeito. Perdida na presencização do hoje, ela entende o 'passado' a partir do 'presente' (GA, I, 2, 517) (HEIDEGGER, 2012, p. 1059).
\end{abstract}

Ou seja, o modo de ser impessoal abdica da decisão pelas possibilidades variadas e projetadas pelo(s) seu(s) próprio(s) passado(s) para simplesmente deixar que os outros (ou ninguém) decidam por ele. O impessoal, neste caso, decide-se por nada, decide-se em ser ninguém, deixando-se ser tudo que está presencizado. Falta ao impessoal, com isso, o que Heidegger chamou de destino [Schicksals], a ação que decide por esta ou aquela possibilidade herdada (os passados) colocada por uma gama de escolhas a serem realizadas pela existência. "Designamos, assim, o originário gestar-se do Dasein que reside no ser-resoluto próprio, gestar-se em que o Dasein, livre para a morte, se entrega a si mesmo por tradição, numa possibilidade herdada e, no entanto, escolhida" (GA, I, 2, 507) (HEIDEGGER, 2012, p. 1039).

$\mathrm{O}$ destino enquanto modo de ser radicalmente pessoal da existência reconhece a sua historicidade de maneira própria, segundo Heidegger. "Só a temporalidade própria, que é ao mesmo tempo finita, torna possível algo assim como destino, isto é, uma historicidade própria” (HEIDEGGER, 2012, p. 1043). Isto é, a existência se encontra com suas possibilidades, reconhece os passados que herdou, e decide o que fazer com tal herança. Isto seria o seu destino, sua marca mais relevante é o confronto com o tempo que lhe é legado ou com as memórias que compõem sua existência. Historicidade, nestes termos, identificase com a memória. Este movimento reflexivo de volta-se necessariamente à própria memória, aos passados herdados, que compõem a própria existência, Heidegger nomeia como o retorno ou repetição [Wiederholung]. 
Não é necessário que o ser-resoluto saiba expressamente a respeito da origem das possibilidades nas quais se projeta. Mas reside certamente na temporalidade do Dasein e somente nela a possibilidade de ir buscar expressamente, a partir do tradicional entendimento-do-Dasein, o poder-ser existencial em que o Dasein se projeta. O ser-resoluto que retorna a si e a si se entrega torna-se, então, repetição de uma possibilidade-de-existência tradicionalmente herdada. A repetição é a tradição expressa, isto é, o retorno às possibilidades do Dasein sido-“aí”. (GA, I, 2, 509) (HEIDEGGER, 2012, p. 1043).

Com efeito, cabe à existência reconhecer a repetição do passado como condição existencial, e entender que, caso abdique da decisão, da escolha e, logo, de seu destino, ninguém escolherá para ele. Quer dizer, a repetição do passado que é também a tradição pode tanto penetrar a historicidade própria da existência por meio da ação decisória, conferindo, assim, um destino à existência, quanto encerrar-se no nada, em ninguém, na impessoalidade. " $^{\text {"A repetição não }}$ se abandona ao passado, nem almeja o progresso” (HEIDEGGER, 2012, p. 1045), bem ao contrário, ela retorna para conhecer seu destino.

A-gente evita a escolha. [...] Perdida na presencização do hoje, ele entende o 'passado' a partir do 'presente'. A temporalidade da historicidade própria, ao contrário, como instante precursor e repetente, é uma despresencização do hoje, e um desacostumarse dos comportamentos usuais de a-gente. (GA, I, 2, 517).

Ao termo, para Heidegger, trata-se de confrontar a impessoalidade, sobretudo o movimento da tradição [Überlieferung], compreendida como transmissão [überliefert], ou seja, como o movimento orgânico que faz transitar de um momento a outro. Nesse sentido, a história seria exatamente o confronto com a tradição (ou transmissão) através do fenômeno da repetição e da decisiva ação de assumir o(s) passado(s) em jogo como composto de sua existência. A história, acionada e elaborada por meio desta potência, nomeada como historicidade própria, origina-se da compreensão apropriada das potências da temporalidade e de uma fuga da impessoalidade.

A historicidade autêntica é, portanto, alcançada através de um ato no qual a resolutibilidade do ser humano é temporalizada como retorno repetido a si mesmo devido a uma possibilidade apreendida, na qual o retorno do Dasein a si mesmo está à frente de si. Na unidade extática do repetido "vorlaufen", quer dizer, nessa unidade de passado e futuro há um tipo específico de presença que envolve a decisividade. (QUIST, 2002, p. 85). 


\section{O passado super-egoico é a tradição atuante no indivíduo pela cultura Contribuição da metapsicologia de Sigmund Freud}

O estudo da metapsicologia freudiana é profícuo para o entendimento do aparato psíquico, cujas três instâncias constitutivas da vida anímica são: 1 - o Isso [Es], a instância físico-biológica primeva, instintiva-involuntária, originária do encéfalo (centro do sistema nervoso) [Gehirn (Nervensystem)]; 2 - o Eu [Ich], a instância da alma ou intelecto, das vontades conscientes-inconscientes e das forças voluntárias-invountárias, originário do limiar entre o Isso e o mundo exterior; 3 - o Super-Eu [Über-Ich], instância que surge da tensão entre o Isso, o $E u$ e o mundo exterior, relacionada à tradição ou à cultura. Assim sendo, Isso, Eu e Super-Eu são três forças que se comunicam e se tencionam dentro do chamado aparelho psíquico. O complexo consciência-inconsciência, apesar de ganhar contornos existenciais imediatos através do $E$ u, perpassa todas as instâncias do aparelho psíquico; constituindo-se como potência meta-psicológica por excelência. Nota-se, nesse sentido, que o caráter temporal das três instâncias é delimitado pelo material que compõe cada uma e que tal característica temporal explica o modo como cada uma se estrutura.

\footnotetext{
Vê-se que o Isso e o Super-Eu, mesmo com todas as suas diferenças fundamentais, apresentam um ponto em comum, ou seja, representam influências do passado: o Isso, as hereditárias; e o Super-Eu, essencialmente as recebidas dos outros, ao passo que o Eu é determinado, sobretudo, pelo diretamente vivenciado, portanto, pelo acidental e pelo atual (GW, XVII, 69) 7 .
}

Para a seguinte reflexão, interessa compreender de modo mais detalhado o Super-Eu, instância psíquica que traduz o conteúdo dado ao indivíduo, gratuitamente por meio da cultura, é sobretudo um processo: a tradição, a transmissão. O Super-Eu cultural [Kultur-Über-Ichs] (GW, XIV, 504), como é também nomeado em Das Unbehagen in der Kultur [O mal-estar na cultura] (1930), uma das obras em que Freud ensaia a análise da coletividade, é descrito em seu papel fundamentalmente transicional entre a cultura dada e o indivíduo em formação cultural.

A analogia entre o processo cultural e o desenvolvimento do indivíduo pode ser ampliada num aspecto importante. Pois é lícito afirmar que também a comunidade forma um Super-Eu, sob cuja influência precede a evolução cultural (GW, XIV, 501). 
Assim como o Super-Eu funciona como instância psíquica que representa “influências do passado [...] recebidas dos outros” (Cf. GW, XVII, 69), ele também representa ou traduz todo "passado cultural [kulturelle Vergangenheit]" (GW, XVII, 138), de acordo com o Abriss.

Caso prefiram-se constatações generalistas e distinções nítidas,
então se pode dizer que o mundo exterior, no qual o indivíduo
[Eu] se encontrará exposto após o desligamento em relação
aos pais, representa o poder do presente; já seu Isso, com suas
tendências herdadas, o passado orgânico, enquanto o Super-
Eu, posteriormente vindouro, representa sobretudo o passado
cultural [...] (GW, XVII, 138).

Freud reconhece o teor ativo da tradição e o poder que ela exerce sobre o indivíduo através do complexo super-egoico, isto é, por meio daquilo que é transmitido como cultura, compreendo-a então enquanto passado que atua de modo a compelir naturalmente o indivíduo em certa direção. "A humanidade não vive inteiramente no presente. Nas ideologias do Super-Eu vive o passado, a tradição da raça e da nação, que dão lugar às influências do presente, muito lentamente [...]" (GW, VX, 73). Entretanto, o complexo superegoico não obedece à direção dada pela tradição sem alguma resistência. A tradição como intercurso da transmissão é, ela mesma, tensão. “O Super-Eu é uma instância explorada por nós; a consciência, uma das funções que a ele atribuímos, a de vigiar os atos e intenções do $E u$ e de julgar, exercendo uma atividade censória" (GW, 14, 496).

Quer dizer, tal como no aparato psíquico individual, o Super-Eu cultural junto ao Super-Eu individual desenvolve-se sob o impacto do $E u$, instância que desvia a direção natural da tradição, conforme o esquema dos atos psíquicos que a metapsicologia estabeleceu. O Eu deforma a tradição para que ela produza sentido. Isto é, da direção dada pela tradição ou pelo complexo super-egoico (Super-Eu cultura/Super-Eu “individual”) desenvolvem-se sentidos diversos, construídos sob o crivo dos princípios que animam o ser do $E u$.

O conceito metapsicológico Super-Eu pode ser traduzido por "tradição", aquilo que é transmitido. Pode-se compreender o complexo super-egoico assim, na forma de passado dado como pronto para o indivíduo enquanto tradição. E para Freud, esse passado atua como uma força unidirecional no indivíduo. Ainda assim, esse unidirecionamento sofre a tensão do $E u$, que, ao termo, desvia tanto ele mesmo quanto o próprio complexo super-egoico por meio das suas exigências instantâneas, adotando novos sentidos para ambos. Tradição 
é, portanto, em Freud, sobretudo uma tensão, uma luta entre diferentes âmbitos da existência, expressão da angústia sempre presente no intercurso da transmissão ou no Super-Eu.

\section{0 perigo próprio à tradição}

\section{A força da tradição}

É notória a caracterização de Walter Benjamin da tradição como força existencial. Ao mesmo tempo em que reconhece o papel decisivo que a tradição possui para a cultura, identifica também a sua potência primeva, qual seja, inabilitar, incapacitar ou suprimir eventuais demandas do presente através da força que o apelo vitorioso da cultura exerce. A cultura possuiria, segundo Benjamin, o impulso que produz a coincidência entre história (ou memória) e tradição. Nos arquivos do trabalho das Passagens ou mesmo em ensaios dos anos 1930, essa interpretação sobre o papel da tradição aparece na qualidade de argumento tácito, ao passo que no texto sobre o conceito de história aparece de modo teórico claro. Vejamos a VI tese.

Articular o passado historicamente não significa conhecêlo "tal como ele propriamente foi". Significa apoderar-se de uma lembrança tal como ela lampeja num instante de perigo. Importa ao materialismo histórico capturar uma imagem do passado como ela inesperadamente se coloca para o sujeito histórico no instante do perigo. O perigo ameaça tanto o conteúdo dado da tradição quanto os seus destinatários. Para ambos o perigo é único e o mesmo: deixar-se transformar em instrumento da classe dominante. Em cada época é preciso tentar arrancar a transmissão da tradição ao conformismo que está na iminência de subjugála. Pois o Messias não vem somente como redentor; ele vem como vencedor do Anticristo. $\mathrm{O}$ dom de atear ao passado a centelha da esperança pertence somente àquele historiador que está perpassado pela convicção de que também os mortos não estarão seguros diante do inimigo, se ele for vitorioso. $\mathrm{E}$ esse inimigo não tem cessado de vencer (GS, I, 2, 595) ${ }^{8}$.

A atitude a ser evitada ou o perigo [Gefahr] é, portanto, precisamente um só: "tornar-se instrumento da classe dominante"; em seu sentido político, nos termos marxistas objetivos, mas também no seu sentido teórico fundamental, visto que a tradição se qualifica como forma natural de se conformar diante da 


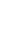

cultura. Ou seja, a tradição [Überlieferung], ou o ato de transmitir [überliefern] não precisa ser o mero ato de transmissão natural entre um antes e um depois, do passado em direção ao presente. Na verdade, essa forma de tradição contém o perigo político da permanência e a consequente ausência de transformações necessárias, que, eventualmente, podem ser suprimidas ou esquecidas pela pressão ou força que a tradição exerce sobre a atualidade no intercurso de seu movimento, a transmissão9.

Para se fugir desse processo naturalizador e perigoso (nas palavras do filósofo), próprio à tradição, Benjamin sugere a consciência ou o reconhecimento dessa natureza da transmissão cultural (tradição), do passado em direção ao presente, mas também da natureza fundamental da temporalidade, qual seja, a estrutura existencial messiânica, no texto Sobre o conceito de história (1940), transposta para os limites culturais da história. "O Messias”, naturalmente, não é o "Cristo" religioso, mas, conforme dito na II tese, uma alegoria do que Benjamin nomeou como "imagem de felicidade", ou "passado não realizado", o fundamento da estrutura existencial da temporalidade proposta por Benjamin. Em suma, o que Benjamin afirma na II tese sobre o conceito de história é a precisamente o passado como limite-criativo do tempo. Seria o passado o princípio que animaria tanto nossa percepção do tempo quanto o próprio fenômeno da temporalidade. O futuro ou o presente seria apenas modos de ser do passado, que, naturalmente incompleto, aberto, contituiria os materiais que das possibilidades de ação e interpretação do mundo. O futuro, aliás, seria o conceito alienador por excelência, tal como se averigua na IX tese. Ao passo que o passado seria o fundamento da experiência, não um lugar de tempo, mas uma força existencial que ontologicamente se estrutura de modo "messiânico".

\section{O passado como fundamento da tradição}

Pertence às mais notáveis particularidades do espírito humano, [...] ao lado de tanto egoísmo no indivíduo, a ausência geral de inveja de cada presente em face do seu futuro", diz Lotze. Essa reflexão leva a reconhecer que a imagem da felicidade que cultivamos está inteiramente tingida pelo tempo a que, uma vez por todas, nos remeteu o decurso de nossa existência. Felicidade que poderia despertar inveja em nós existe tão somente no ar que respiramos, com os homens com quem teríamos podido conversar, com as mulheres que poderiam ter-se dado a nós. Em outras palavras, na representação da felicidade vibra conjuntamente, inalienável, a [representação] da redenção. Com a representação do passado, que a História toma por sua causa, 
passa-se o mesmo. O passado leva consigo um índice secreto pelo qual ele é remetido à redenção. Não nos afaga, pois, levemente um sopro de ar que envolveu os que nos precederam? E as mulheres que cortejamos não têm irmãs que jamais conheceram? Se assim é, um encontro secreto está então marcado entre as gerações passadas e a nossa. Então fomos esperados sobre a terra. Então dos foi dada, assim como a cada geração, que nos precedeu, uma fraca força messiânica, à qual o passado tem pretensão. Essa pretensão não pode ser descartada sem custo. $\mathrm{O}$ materialista histórico sabe disso (GS, I, 2: 693-694).

O passado transitivo, naturalmente inacabado, imperfeito e único (tal como) é, em outras palavras, uma experiência não realizada; a felicidade ou o sentido inacabado [Unabgeschlossene] (GS, V, 1, 589 [N 8, 1] $)^{10}$; o desejo de realizar o irrealizado, assim como diz a proposta de Rudolf Hermann Lotze apropriada por Benjamin. O passado confunde-se com a imagem de felicidade [Bild von Glück] que, latente, vibra, excita-se ao encontrar no agora a possibilidade de realização de felicidades passadas não realizadas, inacabadas. $\mathrm{O}$ “inacabamento do sentido" [die Unabgeschlossenheit des Sinnes] é assim como propõe Jeanne Marie Gagnebin em sua tese doutoral (Cf. 1979), a tônica da ideia de história benjaminiana que localiza a origem desse inacabamento no conceito de passado inacabado, imperfeito, não no futuro. Benjamin não vê no futuro ou na futuridade a abertura [eschlossenheit] para o novo ou o modus do tempo original dos fenômenos da liberdade. Pelo contrário, o passado seria o modus temporal que se abre para a renovação da experiência ou para a atualização do tempo. É o passado o temporalizador da temporalidade. É a partir da abertura do passado que a existência se decide por esse ou aquele destino suspenso em seu interior, de modo "messiâncio", porque “a imagem da felicidade que cultivamos está inteiramente tingida pelo tempo ao qual, uma vez por todas, nos remeteu o decurso de nossa existência"; quer dizer, a posteridade ou a futuridade da existência não é nada mais que, na verdade, impulsos re-formados pelo ter sido [gewesenen] ou passado dessa mesma existência. Não há a possibilidade de se sentir “inveja” do seu futuro, como reitera Benjamin. Ou seja, não há futuro que afete a existência, não há nem mesmo substância futura, mas somente passado(s). Se há futuridade ou futuro, esse é o nome das imagens de felicidade que pulsam em passados não-realizados, imperfeitos, inacabados. O que se nomeia futuro nada mais é do que passado, um modo de ser do passado, portanto; pois qualquer futuro que se configure assim é inteiramente tingido pela experiência passada. $\mathrm{O}$ inacabamento do sentido existencial é originado do passado, naturalmente imperfeito, inacabado. 
Essa é a concepção determinante do conceito de passado benjaminiano, pois o passado é aberto e a origem da abertura para a temporalização da experiência. Isto é, o passado é a origem-criativa, elemento unificador-seccionador do tempo segundo a arquitetura do tempo benjaminiana. Todo passado que é lido agora no agora da sua cognoscibilidade, ou seja, no presente que atualiza ou torna ato a sua presença, é imagem de felicidade perdida ou esquecida que reencontra agora a possibilidade de redenção, de realização. Felicidade na II tese não é "felicidade em si”, mas em relação ao ter sido [gewesenen], ao passado no seu sentido benjaminiano de passado aberto e inacabado que se realiza, torna-se feliz, logo, “não é felicidade passada, é a felicidade que foi possível no passado, mas foi perdida" (HAMMACHER, 2005, p. 38). O encontro gerado pela tênue força messiânica que todo passado possui, força que se encontra na latência de imagens de felicidade, faz emergir aquilo que se chamou de imagem dialética, o encontro do passado com a sua atualidade no tempo-do-agora, a projeção do passado inacabado em forma de imagem feliz que deseja ser realizada realizando-se: o passado.

\section{Esclarecimento sobre a estrutura existencial messiânica}

O termo "messiânico" na obra de Walter Benjamin não se circunscreve ao âmbito da religião, mas se desenvolve em uma direção que vai dos limites judaicos da teologia ao terreno da ontologia, da teoria da história e da filosofia da existência, tal como afirma Jacob Taubes (Cf. WENTZER, 1998, p. 87). Este "messianismo" no seu sentido a-religioso, teológico-histórico-político, diz de determinada estrutura que explica a atualização histórica à qual Jacques Derrida chamou de "messianicity". Nota-se que esse argumento serve para todo o complexo de conceitos teológicos mobilizados por Benjamin.

$\mathrm{O}$ messias bejaminiano não requer um estado pós-histórico para atuação ${ }^{11}$; ao contrário, o messiânico é um aspecto próprio à dinâmica histórica no seu duplo sentido de apreensão e exposição de conteúdos historiológicos, quer dizer, que dizem respeito à lógica da história e da historiografia, pois “o messias suspende a história; o messias não entra em cena no fim de um desenvolvimento” (GS, I, 3, 1243).

Em Marx e Sons (1999), Derrida esforça-se para separar o seu conceito “messiânico" do de Benjamin. O que ocorre, entretanto, a partir da leitura que Werner Hamacher e Fredric Jameson realizaram daquilo que separa o messianismo benjaminiano do de Derrida, é um mal-entendido. A leitura de Hamacher e Jameson, como o próprio Derrida indica, erra ao igualar “messianismo" e “utopia”, o que é insuficiente caso se compreenda o teor profano próprio ao messianismo 
benjaminiano, além de toda a explicação do conceito feita por Benjamin nas suas obras. "Messianicidade [...] é qualquer coisa menos utópico" (DERRIDA, 1999, p. 248), tanto para Derrida quanto para Benjamin; antes, "messianismo" diz respeito à estrutura existencial universal que não pode ser, portanto, reduzida a algum motivo religioso, apesar de ser, sim, teológico: "refere-se, em todo aqui-agora, ao advir de um evento eminentemente real, concreto, quer dizer, a mais irredutível heterogênea alteridade" (DERRIDA, 1999, p. 248). O autor comenta ainda, pouco depois:

\begin{abstract}
Uma messianicidade sem messianismo não é um messianismo diluído, uma redução da força da expectativa messiânica. É uma estrutura diferente, uma estrutura da existência que eu tento levar em conta de modo a referir-me menos às tradições religiosas do que a possibilidades cujas análises eu gostaria de prosseguir, refinar, complicar e contestar (DERRIDA, 1999, p. 250).
\end{abstract}

Derrida propõe a leitura do conceito de "fraca força messiânica” de Benjamin como "messianicidade sem messianismo", quer dizer, messianismo profano, estrutura existencial, não religiosa. E ao evitar igualar "messianismo" a "utopia", o que Hamacher e Jameson não contabilizam nas suas críticas, Derrida esclarece o uso recorrente que Benjamin faz do motivo messiânico na sua obra e em anotações particularmente importantes para a compreensão da constelação temporal que se desenha no texto sobre o conceito de história.

Tal discussão, suscitada pela obra Spectres de Marx (1993) de Derrida, acaba por aproximar Derrida e Benjamin, diferentemente do que Hamacher e Jameson pressupuseram. A compreensão de Derrida do motivo messiânico como estrutura existencial é exatamente o que se lê nas entrelinhas por vezes obscuras dos textos benjaminianos acerca do messianismo histórico. "Messianicidade sem messianismo" (DERRIDA, 1999, p. 250), nas palavras de Derrida, é o refinamento do conceito de "messiânico" não contaminado pela tradição religiosa, mas que assume o teor teológico da experiência histórica, assim como exige a teoria da história de Benjamin, conforme reafirma Daniel Bensaïd em "Jacques Derrida et le messianismo sans Messie” (2001). O passado que espera a sua realização porque é o não-realizado é messiânico; a estrutura do tempo de Benjamin, assim, é messiânica, no sentido de que há um destino suspenso à espera de se realizar, fundamentalmente organizado pelo conceito de passado.

É evidente que a concepção teológica talmúdica do messiânico se estrutura a partir de uma temporalidade que coaduna, de certa maneira, com a forma 
que Derrida e Benjamin propõem para a concepção do que é messiânico, pois a literatura talmúdica enxerga a redenção como algo possível a todo instante. $\mathrm{O}$ Machiah não se insere no registro da futuridade, mas do instante, do tempo-doagora, da efemeridade. Basta lembrar a conhecida história contada no tratado Sanhédrin (98a) do Talmud Bavli, segundo a qual o Rabbi Yoshoua ben Levi, ao encontrar o profeta Elias, pergunta-lhe: quando vem o Messias? Elias responde: pergunte a Ele mesmo (na porta de Roma, onde se encontra junto aos pobres e doentes). Na porta da cidade de Roma, então, ao encontrar o Messias, Rabbi Yoshoua interroga-lhe: Mestre, quando virás? E ouve-se a resposta intempestiva do Machiah: hoje מויה; hayom]. ${ }^{12}$

Nesse sentido, o messiânico não se identifica com algum destino histórico-progressivo direcionado à perfectibilidade humana, mas muito antes pelo contrário, o aspecto messiânico da tradição teológico-talmúdica é interruptivo, instantâneo, efêmero (CAMILLI, 2013). O messiânico, segundo a tradição talmúdica, reafirma a ideia de que a criação original genética é, na verdade, criação contínua, como propõe Rabbi Haïm de Volzone, inspirado pelo Kuzari de Yehuda Halevi.

O conceito de Criação continuada coloca a ideia de que a Criação não é acabada, mas em devir perpétuo [...]. O messianismo aparece então como o movimento que continua o ato criador, de modo que não se considera mais a Criação como acabada, mas como continuada (CAMILLI, 2013, p. 37).

Além disso, é notável que já no século III da nossa era Rabbi Chémouel da Babilônia associava o tempo messiânico ao fim da opressão e da liberação política do povo hebreu, então, exilado, o que não torna menos curiosa a reapropriação da ideia de messias em termos semelhantes séculos depois (Talmud Bavli, Berakhot 34b; Chabat 63a ; Pessahim 68a) (Camilli, 2013, pp. 125-126). A estrutura existencial messiânica benjaminiana tem por finalidade precisamente dar voz aos silenciados, dar nome aos sem nome, despertar o passado oprimido [unterdrückte Vergangenheit] (tese XVII), esquecido, por meio da consciência da natureza própria ao passado, a saber, o que Benjamin nomeia como tênue ou fraca força messiânica [schwache messianische Kraft].

A fraca força messiânica é uma ideia central em Benjamin no texto sobre o conceito de história. Essa fraca força messiânica, fraca carga messiânica, é a possibilidade dada ao homem e a cada geração, mas através de suas aspirações e seus atos mais 
profanos, mais políticos, de deixar aparecer alguma coisa cujo germe no passado talvez tenha falhado, mas pode ainda receber uma nova força (MOSÈS, 2011, p. 97).

Os motivos teológicos na obra benjaminiana não devem em nenhum momento ser compreendidos como reafirmação da religião dentro da filosofia; ao contrário, a teologia, que já é em si a racionalização do discurso religioso, nunca é tomada como verdade revelada por Benjamin, mas como suporte técnico e teórico que possibilita penetrar o teor irracional ou mítico que paira sobre determinados aspectos da modernidade. Quer dizer, "no pensamento de Benjamin, o paradigma teológico não propiciaria uma resposta (religiosa) às perguntas dos homens; antes seria o que abala os edifícios, tão bem construídos, dos sistemas lógicos, especulativos ou políticos” (GAGNEBIN, 1999, p. 201), os quais acreditam na imprecisa pureza racional e normativa dos seus fundamentos, ainda que persistam em repetir padrões mítico-religiosos, como é o caso da ideia de tempo e a sobrevivência da conceitualização ontológico-tradicional. Benjamin, então, ao mobilizar o "messiânico" como estrutura teórica de leitura de certo comportamento próprio ao tempo ou à temporalidade, parece chamar atenção ao fato de que há um padrão teológico capaz de explicar de forma racional o comportamento descontínuo do tempo por meio da estrutura existencial que entende o passado como força e origem ${ }^{13}$, pois é o passado o limite-criativo do tempo que se atualiza diante do tempo-do-agora. Essa estrutura existencial é teoreticamente messiânica, nos termos aqui expostos. ${ }^{14}$

Dito de forma resumida, as alegorias e meditações benjaminianas nos ensinam que se o tempo é algo que continuamente se apresenta, ou seja, se tempo é a possibilidade do acontecimento constante, isso se deve ao fato do passado a substância do tempo - ser incompleto e aberto por natureza; fato expresso pelo estrutura existencial messiânica, cuja marca é precisamente os destinos ou possibilidades do passado suspensos, a espera por uma decisão.

\section{A força vencedora da tradição}

Retornando ao tema da tradição, na VI tese, o “anticristo” é precisamente a tradição no seu sentido naturalizante, o "vencedor" que se apresenta na forma de dado historiológico orgânico para a história. Quer dizer, a tradição possui o dom natural para a imposição da história dos vencedores, e caberia ao historiador materialista (benjaminiano) confrontar este processo, ao acessar o que Benjamin 
chamou de temporalidade "messiânica" e, como afirma a tese subsequente, “escovar a história a contrapelo [die Geschichte gegen den Strich zu bürsten]" (GS, I, 2, 697); o que significa na prática reconhecer no processo de transmissão da tradição uma condição existencial (a mesma da qual fala Heidegger), da qual os passados “não realizados” fazem parte de modo escondido, recalcado, esquecido. A força existencial do passado compõe a tradição, permanece sendo transmitida, porém, em sua forma negativa.

Ao historiador que quiser reviver uma época, Fustel de Coulanges recomenda banir de sua cabeça tudo o que saiba do curso ulterior da história. Não se poderia caracterizar melhor o procedimento com o qual o materialista histórico rompeu. É um procedimento de identificação afetiva. Sua origem é a indolência do coração, a acedia que hesita em apoderar-se da imagem histórica autêntica que lampeja fugaz. Para os teólogos da Idade Média ela contava com o fundamento originário da tristeza. Flaubert, que bem a conhecera, escreve: "Peu de gens devineront combien il a fallu être triste pour ressusciter Carthage". A natureza dessa tristeza tornase mais nítida quando se levanta a questão de saber com quem, afinal, propriamente o historiador do Historicismo se identifica afetivamente? A resposta é, inegavelmente: com o vencedor. Ora, as dominantes de turno são os herdeiros de todos os que, algum dia, venceram. A identificação afetiva com o vencedor ocorre, portanto, sempre, em proveito dos vencedores de turno. Isso diz o suficiente para o materialismo histórico. Todo aquele que, até hoje, obteve a vitória; marcha junto no cortejo de triunfo que conduz os dominantes de hoje [a marcharem] por cima dos que, hoje, jazem por terra. A presa, como sempre de costume, é conduzida no cortejo triunfante. Chamam-na bens culturais. Eles terão de contar, no materialismo histórico, com um observador distanciado, pois o que ele, com seu olhar, abarca como bens culturais atesta, sem exceção, uma proveniência que ele não pode considerar sem horror. Sua existência não se deve somente ao esforço dos grandes gênios, seus criadores, mas, também, a corveia sem nome de seus contemporâneos. Nunca há um documento da cultura que não seja, ao mesmo tempo, um documento da barbárie. $\mathrm{E}$, assim como ele não está livre da barbárie, também não o está o processo de sua transmissão, transmissão na qual ele passou de um vencedor a outro. Por isso, o materialista histórico, na medida do possível, se afasta dessa transmissão. Ele considera como sua tarefa escovar a história a contrapelo (GS, I, 2, 696-697).

Na VII tese sobre o conceito de história, a caracterização da tradição como organizadora da cultura e naturalizadora da história do "vencedor" aprofundase. A recomendação de Fustel de Coulanges é flagrante e pretende, efetivamente, 
o esquecimento do depois [spätern] (o presente), propondo a possibilidade de imersão completa no “antes” ou no passado no seu sentido puro. Isto é, Coulanges vê a cultura como produto da tradição que nada mais seria do que a transmissão natural entre um “antes” e um “depois”, do passado em direção ao presente. A crítica à tradição aparece, então, como crítica à sua forma científica, a saber, a historiografia "historicista" (a citação do adágio rankeano logo ao início da VI tese não deixa dúvidas). A empatia [Einfühlung], método exemplar da escola histórica alemã (historiografia historicista) e metodismo francês (ou da "escola histórica científica”), seria um mero produto da organicidade que a tradição produz; pois se a tradição organiza naturalmente a direção da temporalidade, não há escolha, o vencedor será o lembrado, o vencedor será afetivamente o feitor da tradição, realizador da cultura, e, por fim, agente e sobretudo condutor original da história. Assim, a cultura é denunciada como a comemoração intermitente da barbárie do vencedor sobre o vencido que, com efeito, é esquecido, não-histórico ${ }^{15}$.

A forma para se desviar a direção da tradição anunciada na VI tese é, na VII tese, repetida: afastar-se da transmissão cultural própria a esse processo, reconhecendo a sua estrutura fundamental sob a égide da tradição e, por conseguinte, ativar a temporalidade "messiânica" acionando, com isso, as possibilidades de sentido historiológico suprimidas pela tradição, aquilo que não se transmite e permanece negativamente, ou aquilo que nem mesmo se transmite e permanece como vestígio: os passados "não-realizados”, as “imagens de felicidade”. Ou seja, “escovar a história a contrapelo" (ir contra a direção da tradição), nos termos alegóricos benjaminianos. O historiador materialista, então, tem a tarefa de interromper o cortejo do vencedor, a transmissão dos monumentos de cultura, pois são monumentos da barbárie inexorável à direção "vitoriosa” que a história assume como sua sem a devida interferência. O trabalho do materialista histórico, de acordo com Benjamin, é interromper tal transmissão, descontinuar a tradição, "explodir o contínuo da história”, de maneira descontínua; anunciar aquilo que está reprimido, recalcado, esquecido: o "passado oprimido", conforme a XVII tese, o "vencido". Dessa forma, outra história seria possível.

“Que 'as coisas continuem assim' - eis a catástrofe [Daß es »so weiter« geht, ist die Katastrophe]" (GS, V, 1, 592 [N 9a, 1]), uma vez que a “catástrofe” é a norma da tradição (GS, V, 1, 591 [N 9, 4]), quando não interrompida, não atualizada, retirada da sua inércia natural (da transmissão entre passado e presente). É o que se averigua alegoricamente pela figura do “anjo" da IX tese sobre o conceito de história: o Progresso como um vento irresistível que impele a história para o futuro, impedindo-a de conhecer o passado, logo à sua frente, arrebatando a 
história para a direção "catastrófica”, destituída de sentido, mantendo as coisas como estão segundo o movimento normativo da tradição.

\section{Heidegger, Freud e Benjamin ajudam a explicar a condição histórica}

A conhecida fórmula de Reinhart Koselleck (2000) para explicar a condição hermenêutica histórica, a qual Martin Heidegger e Hans-Georg Gadamer (1990 [1960]) filosoficamente já haviam apresentado, situa-se exatamente neste campo de investigação. O “espaço de experiência [Erfahrungsraum]” do qual fala Koselleck é precisamente a tradição em intercurso de transmissão; o "horizonte de expectativas [Erwartungshorizont]", nomeado como "futuro" por ele mesmo e seus intérpretes, segundo uma leitura teórico-ontológica de Heidegger e Gadamer, seria, na verdade, as possibilidades disponibilizadas pelos passados, então, herdados. Isto é, o conjuto de situações hermenêuticas proposto por Koselleck, chamado por ele de "tempo histórico", pode ser também entendido como uma evidência relevante e já amplamente aceita entre os historiadores do papel da tradição na construção do mundo histórico.

Naturalmente, não se trata de afirmar que Koselleck se equivoca ao associar o "horizonte de expectativas" ao "futuro", mas somente de precisar que tais conceitos encontram sua pertinência no âmbito epistemológico do condicionamento da construção do mundo histórico, ou seja, na análise do ato de compreensão hermenêutica ou elaboração da experiência. Do ponto de vista ontológico, isto é, do escrutínio do "ser do tempo" e das disposições existenciais que condicionam ou possibilitam a situação hermenêutica histórica (Gadamer), pode-se concluir que o que Koselleck nomeia "futuro" nada mais seria que um "modo de ser do passado” (DE CARVALHO, 2018), sinal da imperfectbilidade da existência, suas não-realizações (Benjamin), desejos, pulsões (Freud), seus limites que são por definição suas possibilidades (Heidegger); pois é precisamente no passado que se encontra o caráter aberto da experiência, a origem do fenômeno do inacabamento do sentido da existência, da impermanência ou transitoriedade como destino insuperável, fenômenos que agrupamos tradicionalmente sob o epíteto "o tempo".

Como tradição, compreende-se, a partir do itinerário aqui desenhado, o ato necessário da transissão: cultural, orgânica, impessoal. O impessoal e o SuperEu são a tradição e a transmissão naturalizadas, sem a interferência da qual fala Benjamin. Contudo, não são apresentados por Heidegger, Freud e Benjamin como condições incontornáveis. O impessoal é apenas um dos modos de ser da existência, o Super-Eu, uma das instâncias psíquicas individuais (ou coletivas), e a tradição de 
Benjamin, na forma de processo de transmissividade, é passível de interrupção ou desvio. Ao penetrar a temporalidade e afirmar-se de maneira a decidir por si mesmo, a existência projeta-se de maneira a se afetar completamente pelo tempo passado, o único tempo que lhe cabe, ensina Benjamin. É como Heidegger diz: “o Dasein, portanto, pode ou ser provido de sentido ou ser desprovido de sentido [Dasein kann daher sinnvoll oder sinnlos sein]" (GA, I, 2, 201). Isto é, a existência pode atribuirse sentido(s) ao reconhecer-se condicionada temporalmente, ou pode se deixar direcionar segundo o impessoal, o Super-Eu freudiano ou a tradição benjaminiana.

Tradição não é história, ou memória (individual, coletiva ou cultural), muito menos historiografia, apesar de haver semelhanças entre as três. "Para Heidegger e Benjamin [...] a tradição não era a transmissão serena e ininterrupta do passado para o presente, mas uma transferência cheia de perigos e risco" (CAYGILL, 1997, p. 28). "Tanto para Heidegger quanto para Benjamin, a tradição é o evento de transmitir e não meramente a transmissão de eventos” (CAYGILL, 1997, p. 36). Não apenas para Heidegger e Benjamin, mas também para Freud, a tradição contém uma dupla potência. Ela é precisamente o ato transmissor natural entre o passado e a atualidade, entre o antes e o depois. Por outro lado, a tradição como transmissão pode ser interrompida, desviada, deformada, transformada, dando acesso ao indivíduo e à comunidade; ela pode inclusive abrir outras formas de se interpretar a sua própria substância, o passado, precisamente porque a tradição também possui a potência de iluminar as descontinuidades entre os passados e o tempo-do-agora; isto é, ao passado cabe continuar ou interromper a transmissão da tradição, cujo papel na construção do mundo histórico é fundamental, pois exprime, simultaneamente, sua condição e suas possibilidades.

\section{Referências}

BENJAMIN, Walter; TIEDEMANN, Rolf; SCHWEPPENHAUSER, Hermann. Gesammelte Schriften. Frankfurt am Main: Suhrkamp, 1991. (GS)

BENJAMIN, Walter; RAULET, Gérard. Werke und Nachlaß. Kritische Gesamtausgabe - Band 19: Über den Begriff der Geschichte. Frankfurt am Main: Suhrkamp, 2010. (Werke und Nachlaß).

CAMILLI, Coralie. Le temps et la loi. Paris: PUF, 2013.

CAYGILL, Howard. Benjamin, Heidegger e a destruição da experiência. In: BENJAMIN, Andrew; OSBORNE, Peter. (org.). A filosofia de Walter Benjamin: destruição e experiência. Rio de Janeiro: Zahar, 1997. p. 17 - 46.

DERRIDA, Jacques.Marx \& Sons.In:SPRINKER, M.GhostlyDemarcations: a symposium on Jacques Derrida’s Spectres of Marx. New York: Verso, 1999. p. 213 - 269. 
DE CARVALHO, Augusto. A descoberta do paradoxo fundamental da ideia de tempo e a constituição ontológica do conceito de passado. In: DE CARVALHO, Augusto; MENDES, Breno; RAMALHO, Walderez (org.). Sete ensaios sobre história \& existência. Porto Alegre: Editora Fi, 2018. p. 91 - 110.

FREUD, Sigmund. Studienausgabe. Frankfurt am Main: S. Fischer Verlag, 1975. (SA)

FREUD, Sigmund. Gesammelte Werke. London: Imago, 1941. (GW)

FREUD, Sigmund. Compêndio de Psicanálise. Belo Horizonte: Autêntica, 2014.

GADAMER, Hans-Georg. Wahrheit und Methode, I Band - Hermeneutik. Tübingen: J. C. B. Mohr (Paul Siebeck), 1990.

GAGNEBIN, Jeanne-Marie. Über den Begriff der Geschichte. In: LINDNER, Burkhardt. (org.). Benjamin Handbuch: Leben-Werke-Wirkung. Stuttgart, Weimar: J. B. Metzler, 2011a. p. 284 - 300.

GAGNEBIN, Jeanne-Marie. Seis teses sobre as “Teses”. In: CARRIERI, Alexandre; GOBIRA, Pablo; FABRI, Bruno (org.).Lado "B”[enjamin]. Belo Horizonte: Crisálida, 2011b. p. $6-25$.

GAGNEBIN, Jeanne-Marie. Teologia e Messianismo no pensamento de Walter Benjamin. Estudos Avançados, São Paulo, v. 37, p. 191 - 206, 1999.

GAGNEBIN, Jeanne-Marie. Zur Geschichtsphilosophie Walter Benjamins:die unabgeschlossenheit des sinnes. Erlangen: Verlag Palm \& Enke, 1979.

HAMMACHER, Werner. Now: Walter Benjamin on historical time. In: BENJAMIN, Andrew (ed.). Walter Benjamin and History. London: Continuum, 2005. p. 38 - 68.

HEIDEGGER, Martin. Gesamtausgabe. Frankfurt am main: Vittorio Klostermann, 1977. (GA)

HEIDEGGER, Martin. Ser e tempo [Sein und Zeit]. São Paulo: Editora da Unicamp: Vozes, 2012.

KOSELLECK, Reinhart. Vergangene Zukunft. Zur Semantik geschichtlicher Zeiten. Frankfurt am Main: Suhrkamp, 2000.

LAMBAUER, Barbara; HAPPE, Katja; MAIER-WOLTHAUSEN, Clemens. Die Verfolgung und Ermordung der europäischen Juden durch das nationalsozialistische Deutschland 1933-1945: West- und Nordeuropa Juni 1942-1945. München: De Gruyter Oldenbourg, 2014.

LÖWY, Michael. Walter Benjamin: aviso de incêndio: uma leitura das teses sobre o conceito de história. São Paulo: Boitempo, 2005.

MOSĖS, Stéphane. Figures Philosophiques de la Modernité Juive. Paris: Les éditions du Cerf, 2011. 
QUIST, Wenche Marit. When your past lies ahead of you - Kierkegaard and Heidegger on the Concept of Repetition. KIERKEGAARD Studies Yearbook, Berlin, v. 1, p. $78-92,2012$.

SCHOLEM, Gershom. O Golem, Benjamin, Buber e outros justos. São Paulo: Perspectiva, 1994.

SCHOLTZ, Gunter. Das Historismusproblem und die Geisteswissenschaften im 20. Jahrhundert. Archiv für Kulturgeschichte, [Erlangen], v. 2, p. 463 - 486, 1989.

TROELTSCH, Ernest. Das Neuzehnte Jahrhundert. In: Gesammelte Schriften (Bd 4). Tübingen: Verlag von J. C. Mohr (Paul Siebeck), 1913. p. 614 - 149.

WENTZER, Thomas Schwartz. Bewahrung der Geschichte: die hermeneutische philosophie Walter Benjamins. Bodenheim: Philo Verlagsgesellschaft, 1998.

WIZISLA, Erdmut. Renoncer à produire du rêve ? Le messianisme politique chez Benjamin et Brecht. In: LAVELLE, Patricia. (dir.). Walter Benjamin. Paris: Éditions de l'Herne, 2013. p. 303 - 308.

\section{Notas}

${ }^{1 *}$ Agradeço à FAPES e à CAPES pelo financiamento da pesquisa.

${ }^{2}$ Doutor em História pela UFMG. Professor e Pesquisador do PPGH-UFES (pós-doutorado)

${ }^{3} \mathrm{~A}$ escolha do trio Heidegger, Freud e Benjamin não é arbitrária. Evidentemente os três não são os únicos pensadores a tratar do problema da tradição como transmissão existencial/cultural em sua relação com o fenômeno histórico. Hans-Georg Gadamer ou Paul Ricoeur, por exemplo, são dois outros filósofos relevantes que pensaram esse mesmo problema. Contudo, escolho os três por encontrar em suas respectivas meditações a conexão imediata entre o problema da tradição como transmissão e a afirmação do passado como átomo fundamental da ideia de tempo, fato que induz a reflexão em direção ao problema do "fator histórico" de modo a justificá-la ontologicamente. Não por acaso, tanto Ricoeur quanto Gadamer recorrem à obra de Heidegger (Ricoeur à de Freud também) quando desenvolvem suas teorizações sobre o problema da tradição e da história.

${ }^{4}$ Assim traduz Fausto de Castilho o vocábulo Man (Cf. HEIDEGGER, 2012).

${ }^{5}$ As edições das obras completas utilizadas (de Heidegger, Freud e Benjamin) serão citadas conforme as abreviações indicadas nas referências bibliográficas, seguindas do número do volume, tomo e página, separados por vírgula.

${ }^{6}$ Há, na teoria sobre a banalidade do mal, em Hannah Arendt uma perspectiva semelhante, pois o mal "banal”, apesar de encarnar sempre na humanidade, não seria cometido por "ninguém".

${ }^{7}$ Exclusivamente para esse texto será usada a edição das Obras Incompletas de Sigmund Freud publicada sob a direção editorial de Gilson Iannin. A tradução é de Pedro Heliodoro Tavares (Cf. FREUD, 2014).

${ }^{8}$ As traduções das teses ligeiramente modificadas seguem a obra de Michael Löwy (2005). 
${ }^{9}$ Corrobora-se aqui a intepretação da professora Jeanne-Marie Gagnebin: "Benjamin besteht, stärker als die meisten Marxisten seiner Zeit, auf der Bedeutung der Überlieferung, insbesondere der kulturellen Werke, Einzig die Auseinandersetzung mit dem Überlieferungsbegriff- ein alltäglicher, konkrete, weniger symbolisch aufgeladener Begriff als der in gewissem Sinne synonyme der Tradition - erlaube dem Historiker eine kritische Reflexion nicht nur der Vergangenheit, sondern zugleich und untrennbar auch der eigenen Gegenwart. Wenn ein bestimmten Moment der Gegenwart mit einem bestimmten Moment der Vergangenheit »passend « zusammentrifft, ereignet sich eine Art Erschütterung, die beide gleichsam in neuem Licht erscheinen lässt und dazu beiträgt, sie dem herrschenden Konformismus zu eintreissen" (GAGNEBIN, 2011a, p. 286). Nesse sentido, nota-se a distinção vocabular que Benjamin empreende. Tradition e überlieferung são diferentes, para Benjamin. Enquanto überlieferung diz respeito ao ato de transmitir um passado ao presente, Tradition diz respeito à memória em relação a hábitos, estórias, experiências. Sumariamente, überlieferung é o fenômeno concreto da ideia de Tradition.

${ }^{10}$ Igualmente, Martin Heidegger entende que "na essência da constituição-fundamental do Dasein reside uma constante incompletude. A não-totalidade significa um algofaltante no poder-ser [Im Wesen der Grund-verfassung des Daseins liegt demnach eine ständige Unabgeschlossenheit. Die Unganzheit bedeutet einen Ausstand an Seinkönnen.]” (GS, I, 2, 314). Todavia, nota-se que há uma diferença radical entre cada uma das estruturas que explica o inacabamento existencial, a saber, para Benjamin, o passado é a origem do inacabamento, para Heidegger, a futuridade é a sua origem. Notase, finalmente, que para as citações da obra das Passagens, o número do fragmento será adicionado entre colchetes.

${ }^{11}$ Tese bastante difundida entre estudiosos da obra de Benjamin, que, no entanto, não parece advir da compreensão exata do teor histórico-temporal do que é messiânico. Em sentido contrário à compreensão do teor "messiânico" da obra de Benjamin proposta por Erdmut Wizisla (Cf. WIZISLA, 2013), a argumentação a seguir reconhece o teor teológico da obra benjaminiana enquanto artifício teórico mobilizado de maneira a-religiosa. Há uma diferença crucial entre teologia e religiosidade. Enquanto a primeira requer a razão, a última dispensa sua necessidade. Benjamin se move, sempre, no terreno da teologia. A consciência de que Benjamin se apropria de tradições teóricas diversas, tais como a marxista, a teológica, a romântica, a crítico-literária, a estética, a historiológica, a social, a fim de tornar todas essas perspectivas teóricas o material da sua interpretação sempre sui generis e heterodoxa de qualquer que seja a questão é o princípio que anima a impossibilidade de se afirmar qualquer ligação religiosa ao pensamento benjaminiano, mesmo que travestida na forma política, algo que se torna claro por meio da crítica à teocracia que se encontra no Theologisch-politisches Fragment (GS, II, 1, 203). Mesmo que Benjamin tenha sugerido que o conceito marxista de sociedade sem classes seja a secularização do tempo messiânico religioso em uma nota pessoal (GS, I, 3, 1231 [Benjamin-Archiv, Ms 1098v]), não é razoável deduzir disso à coincidência entre o que Marx fez e o que Benjamin tenta realizar nas suas teses sobre o conceito de história. A constatação benjaminiana sobre o que Marx realizou com o teor messiânico próprio ao conceito de sociedade sem classe se assemelha mais a uma crítica do que a um acordo. "Defendo a hipótese de que a presença de motivos teológicos e messiânicos no pensamento de Benjamin não tem por alvo defender uma aliança da religião e do socialismo (uma interpretação bastante em voga), mas, pelo contrário, quer solapar as certezas político-religiosas sobre o fim feliz da história da humanidade pelo ácido 
da reflexão teológica autêntica: a saber, uma reflexão que não procura responder às questões sem solução da humanidade (o mal, a dor, a morte), o que é a grande tentação da religião, mas que lembra sempre que nenhum discurso (logos) humano pode realmente dizer Deus (theos), que nenhum discurso humano pode pretender a um saber absoluto, em particular nenhum saber absoluto sobre o curso da história” (GAGNEBIN, 2011b, p. 20). A teologia é um elemento disruptivo, portanto. Apesar disso, e ainda junto a isso, a teologia possui uma forma bastante eficaz e propositiva dentro da obra benjaminiana na qualidade de ferramenta dotada da potência de penetrar o ambiente irracional do mundo material e do espírito; a teologia consegue, além de penetrar o reino da irracionalidade, algo que outros elementos conceituais e ideais não conseguem, a saber, trazê-los até os limites da razão e da compreensão.

${ }^{12}$ Reafirma-se que o conceito de messiânico em Benjamin não surge sob a influência unânime de Ernst Bloch, mas advém de seu conhecimento sobre o judaísmo, algo declarado no apêndice B das teses. (SCHOLEM, 1994, p. 211). Conforme aponta Scholem, Benjamin tinha bom conhecimento do assunto por meio das leituras de Philosophie der Geschichte, oder über die Tradition, obra sobre a kaballah de Franz Molitor; Die Thora im Hersen, de Achad Haam; Der Stern der Erlösung, de Franz Rosenzweig (SCHOLEM, 1994, p. 204 - 205).

${ }^{13}$ Nota-se, a essa altura do argumento, que em Benjamin, a origem [Ursprung] é uma categoria que não se confunde com a gênese [Entstehung], pois esse início expressa a restauração do que vem a ser pela extinção de outro ser, bem como testemunha as coisas como incompletas, inacabadas [Unvollendetes, Unabgeschlossenes] (GS, I, 1, 226).

${ }^{14}$ De acordo com o professor Michael Löwy, “[...] o equivalente - o 'correspondente' - profano do Messias são os núcleos de resistência antifascista, as futuras massas revolucionárias herdeiras da tradição de junho de 1848 e de abril-maio de 1871. Quanto ao Anticristo - um teologúmeno cristão que Benjamin não hesita em integrar em seu argumento messiânico de inspiração explicitamente judaica - seu homólogo secular é, sem dúvida alguma, o III Reich hitlerista" (LÖWY, 2005, p. 68). O que, claramente, é uma hipótese. Entretanto, prefere-se enxergar no texto de Benjamin a mera descrição teórica (“armadura teórica") que ele mesmo diz produzir (Werke und Nachlaß, 19, 311).

${ }^{15}$ Resultado concreto do que Benjamin denuncia na VII tese é a Shoah que nos anos seguintes à escrita do texto ganhará contornos práticos radicais. E é no mínimo curioso ler o que Jonas Cahen (sobrevivente dos campos de Westerbork, mas também de Theresienstadt e Auschwitz) registra em uma carta para familiares. De dentro do campo de Westerbork, na Holanda ocupada, ele diz: "A era da civilização - 'A Alemanha venceu em todas as frentes', 'traz cultura e civilização!' Civilização, quando se encontram pessoas em carrinhos de mão, em mochilas, ou simplesmente estendidas no chão? Cultura, quando se vê uma mãe desesperada, porque não consegue alimentar seu filho... sem leite” (LAMBAUER et al., 2014, p. 310). Para ele, a cultura assume dentro da história europeia um duplo sentido: simultâneo cumprimento e negação das promessas da civilização. As semelhanças com o julgamento de Benjamin sobre a cultura e a civilização são flagrantes. 